\title{
URETHRAL METASTASIS OF LUNG CARCINOMA WITH GERMINATIVE CELL FEATURES
}

\author{
MARCOS V. TEFILLI, STEPHEN D. STEFANI, MIRANDOLINO B. MARIANO \\ Department of Urology and Oncologic Clinic, Mãe de Deus Hospital, Porto Alegre, RS, Brazil
}

\begin{abstract}
Introduction: We present the case of a patient with urethral metastasis of a lung carcinoma with germinative cell features.

Case Report: A White, 57-year old man underwent urologic assessment due to gross hematuria. Patient was being treated with chemotherapy and radiotherapy during the past 3 months due to primary carcinoma of the lung with brain metastasis. Urethrocistoscopy and nuclear magnetic resonance imaging revealed a stenosing mass invading the bulbomembranous urethra. No other tumor was found. Biopsy specimens, obtained from the lung, brain and urethra tumors, revealed the same neoplasia, with definitive diagnosis being undifferentiated giant cell carcinoma of the lung with germinative features. Considering his clinical condition and poor prognosis, a decision was made to treat the patient only clinically. Clinical conditions deteriorated and the patient evolved to death within 3 months.

Comments: As far as we were able to access, urethral metastasis from lung carcinoma had never been described in the indexed literature. Due to the extremely limited experience with these tumors, there is not a defined treatment and the prognosis remains quite poor.
\end{abstract}

Key words: urethra; metastasis; lung cancer; germ cell cancers

Int Braz J Urol. 2003; 29: 431-3

\section{INTRODUCTION}

Urethral cancer is rare, corresponding to less than $1 \%$ of all malignant neoplasias in humans. Until now, approximately 650 cases of primary carcinoma of urethra were reported in the English-language literature, most often epidermoid carcinomas $(1,2)$. Secondary involvement of the urethra by malignant tumors is uncommon, unless there is direct invasion from primary neoplasias of adjacent organs (2). We report a case of urethral metastasis secondary to a primary carcinoma of the lung with germinative cells features. According to the bibliographic review conducted, this is the first case reported in the literature.

\section{CASE REPORT}

Male, White, 57-year old patient is referred for urologic evaluation due to gross hematuria. He had been treated with chemotherapy and radiotherapy during the past 3 months due to primary giant cell carcinoma of the lung with brain metastases. No abnormalities were detected on the urologic assessment.

The qualitative assay of urine revealed microscopic hematuria and serum tests revealed chorionic gonadotrofin (hCG) of $55 \mathrm{mIU} / \mathrm{mL}$ and mild anemia. The upper urinary tract was assessed by echography and no abnormalities were detected. Urethrocystoscopy showed a stenosing lesion in the urethra, which invaded its bulbomembranous portion, 


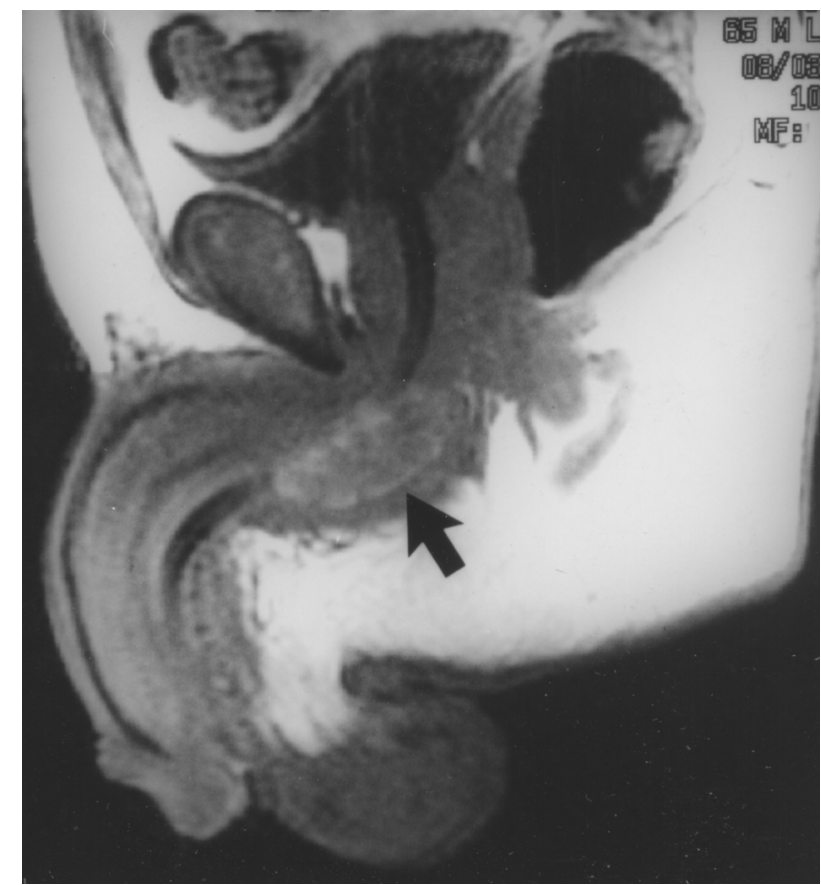

Figure 1 - Nuclear magnetic resonance imaging showing urethral metastatic lesion (arrow).

without evidence of prostatic or vesical involvement. Nuclear magnetic resonance imaging of the pelvis evidenced a single solid lesion measuring approximately 4.7 x $1.9 \mathrm{~cm}$ invading the bulbomembranous urethra (Figure-1). No other tumoral lesion was found in any other location.

Biopsy specimens obtained from lung, brain and urethra contained the same neoplasia, with the histological diagnosis being defined as undifferentiated giant cell carcinoma of the lung with germinative features. Microscopically, the biopsies presented a combination of atypical polygonal cells and some multinucleated giant cells, suggesting the dysmorphic pattern of choriocarcinoma (Figure-2). Extensive areas of necrosis and hemorrhage occupied a large proportion of the tumor and there was no squamous or glandular differentiation. Immunohistochemical analysis revealed positivity for hCG in isolated giant cells and multifocal positivity for alpha-fetoprotein in the polygonal cells. Cytokeratins $(\mathrm{AE} 1+\mathrm{AE} 3)$ were diffusely positive.

With every therapeutic possibility depleted and presenting poor clinical conditions for any addi- tional therapy, the patient showed a progressive deterioration of his clinical condition and died within 3 months. During this period, he persisted with eventual gross hematuria and developed an acute urinary retention, which was treated with suprapubic catheterization.

\section{DISCUSSION}

Urethral metastases from lung carcinomas were never reported in the literature. The main sources of metastatic tumors to the urethra are the gastrointestinal tract, the bladder and the prostate, almost always invading it by contiguity $(1,2)$. The disease's presentation pattern in this case, giant cells carcinoma of the lung with germinative features and urethral metastasis, is unique and a hematologic dissemination route would be the most probable explanation.

Primary choriocarcinoma of the lung is the main differential diagnosis to be considered with the undifferentiated giant cell carcinoma of the lung with germinative features (3). Clinically, metastatic tumors from other potential sites such as gonads or mediastinum to the lung must be excluded $(2,3)$. With only 22 cases of primary choriocarcinoma of the lung reported, the diagnosis is established basically according to the same criteria used for the diagnosis of gestational choriocarcinoma (3). The differential histopathological diagnosis between primary choriocarcinoma of the lung and undifferentiated giant cell car-

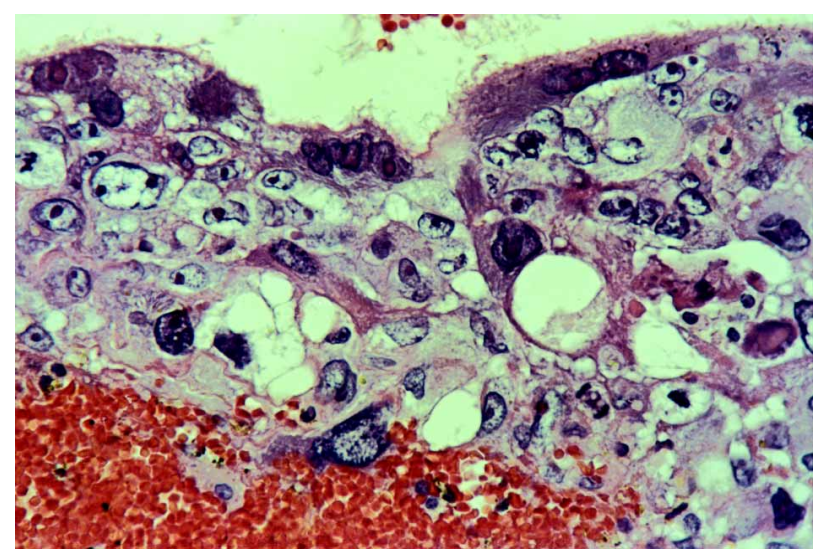

Figure 2 - Photomicrography of urethral neoplasia showing sincitiotrophoblast-like giant cells (above), recovering the large and vacuolized polygonal cells (below), HE X250. 
cinoma of the lung with germinative features is difficult and sometimes arbitrary, since the differences between them are often subjective and dependant on a proper sampling. While the primary choriocarcinoma of the lung contains a large amount of multinucleated cells, similar to the sincitiotrophoblast, which will present a strong immunoreactivity for hCG, those are not very frequent in undifferentiated giant cell carcinomas of the lung with germinative features. These histopathological and immunohistochemical findings are reflected in the serum values of hCG, which tend to be much higher in cases of primary choriocarcinoma of the lung (above 1000 $\mathrm{mIU} / \mathrm{mL}$ ) (3). The malignant potential of the primary choriocarcinoma of the lung is comparable to that of the undifferentiated giant cell carcinoma of the lung with germinative features and, in both cases, is extremely high.
Considering the limited experience with this type of neoplasia, therapeutic recommendations cannot be made. These tumors have an aggressive behavior and the prognosis is uniformly serious.

\section{REFERENCES}

1. Ray B, Canto AR, Whitmore WR Jr: Experience with primary carcinoma of the male urethra. J Urol. 1977; 117: 591-4.

2. Tefilli MV, Gheiler EL, Shekarriz B, Oliveira JG, Tiguert R, Grignon D, et al.: Primary adenocarcinoma of the urethra with metastasis to the glans penis: successful treatment with chemotherapy and radiation therapy. Urology. 1998; 52: 517-9.

3. Ikura Y, Inoue T, Tsukuda H, Yamamoto T, Ueda M, Kibayashi Y: Primary choriocarcinoma and human chorionic gonadotrophin-producing giant cell carcinoma of the lung: are they independent entities? Histopathology. 2000; 36: 17-25.

Received: April 4, 2003

Accepted after revision: July 17, 2003

\author{
Correspondence address: \\ Dr. Mirandolino Batista Mariano \\ Rua Costa, 30 / 803 \\ Porto Alegre, RS, 90110-270, Brazil \\ Fax: + 5551 3231-7247 \\ E-mail: mariano.ez@terra.com.br
}

